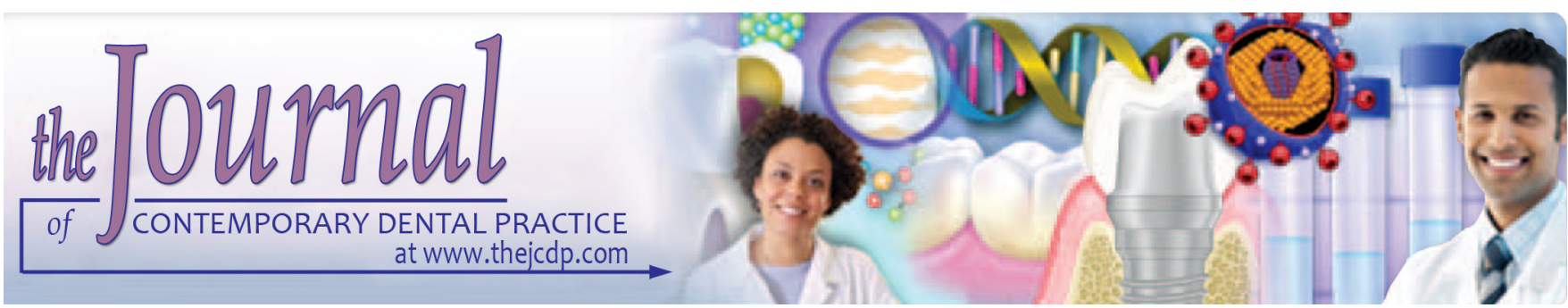

\title{
Shaping Ability of ProTaper Universal, ProTaper NEXT and WaveOne Primary in Severely Curved Resin Blocks
}

\author{
${ }^{1}$ Saeid Tavanafar, ${ }^{2}$ Pouyan Vakili Gilani, ${ }^{3}$ Abdulrahaman Mohammed Saleh, ${ }^{4}$ Edgar Schäfer
}

\begin{abstract}
Aim: Complex anatomy of roots requires endodontic rotary instruments that respect and follow that anatomy. The purpose of this study was to compare the shaping ability of three engine-driven nickel-titanium instruments in severely curved simulated canals.

Materials and methods: Forty-eight severely curved simulated canals in resin blocks were prepared to an apical size of 25 using the following systems ( $n=16$ per group): ProTaper Universal (PTU), ProTaper NEXT (PTN), and WaveOne Primary (WO) (all Dentsply Maillefer, Ballaigues, Switzerland). Composite images were made from the superimposition of pre- and post-instrumentation images. The amount of resin removed by each system was measured by using a digital template and image analysis software. Shaping ability of each system was compared using different parameters: total resin removal, centering ability, canal transportation in the apical, middle and coronal third of canal. Preparation times were also recorded. The data were statistically analyzed by using analysis of variance, paired t-test, and Tukey's post hoc test.
\end{abstract}

Results: Canals prepared with PTN were better centered in the apical part than those prepared with WO and PTU $(p<0.05)$. WO removed significantly more resin at the outer aspect of the maximum point of curvature. WO and PTU caused similar canal transportations at 7 points out of 11 measuring points. At measuring points 3,4 , and 5 WO caused more canal straightening than PTU. Instrumentation with PTU required more time than with the two other instruments $(p<0.05)$. No preparation error or instrument separation occurred.

\footnotetext{
${ }^{1}$ Department of Oral and Maxillofacial Surgery, School of Dentistry, Shiraz University of Medical Sciences, Shiraz, Islamic Republic of Iran

${ }^{2,3}$ Department of Restorative Dentistry, Ajman University of Science and Technology, Ajman, United Arab Emirates

${ }^{4}$ Central Interdisciplinary Ambulance in the School of Dentistry, University of Münster, Münster, Germany
}

Corresponding Author: Saeid Tavanafar, Department of Oral and Maxillofacial Surgery, School of Dentistry, Shiraz University of Medical Sciences, Shiraz, Islamic Republic of Iran, Phone: +987132334481, +989170009179, e-mail: tavanafar@sums.ac.ir, s.tavanafar@gmail.com
Conclusion: In the apical part of the canals PTN obtained the best results with regard to canal transportation.

Clinical Significance: All of the rotary instruments were safe in preparing severely curved canals and PTN showed better preparation of apical part of the canal.

Keywords: Nickel-titanium, ProTaper NEXT, Resin blocks, Shaping ability, WaveOne.

How to cite this article: Tavanafar S, Gilani PV, Saleh AM, Schäfer E. Shaping Ability of ProTaper Universal, ProTaper NEXT and WaveOne Primary in Severely Curved Resin Blocks. J Contemp Dent Pract 2019;20(3):363-369.

\section{Source of support: Nil}

Conflict of interest: All the authors have contributed significantly to the preparation of the manuscript and approved and agreed with the submission to your esteemed journal.

\section{INTRODUCTION}

Creation of a continuously tapered funnel-shaped root canal is a major goal of root canal instrumentation. It aimed to enlarge the canal lumen as practical as possible while respecting the original canal configurations. ${ }^{1}$ Achieving this objective is challenging in narrow and curved canals. ${ }^{2}$ Common problems in these situations are the transportation of the apical foramen, ledge formation, zip, perforation, and instrument separation, which can hinder further canal disinfection and obturation, thereby reducing the ultimate success of root canal therapy. ${ }^{3,4}$ Since the introduction of rotary nickel-titanium instruments (NiTi), there have been continuous evolutions in different aspects such as instrument designs, metallurgical properties of various alloys and working motions. Numerous NiTi instrumentation techniques with different kinematics are associated with easier and faster canal preparation, less iatrogenic errors, and better maintenance of the original canal shape. .,5 $^{3}$

The single-file reciprocating technique is suggested to use only a single instrument to perform the entire 
root canal instrumentation. ${ }^{6}$ WaveOne (WO, Dentsply Maillefer, Ballaigues, Switzerland) is a reciprocating single-file system. It features a novel NiTi alloy (M-Wire), variable tapers along the working part of the instrument and an unequal reciprocating motion. ${ }^{7}$ The reciprocating motion increases fatigue resistance of instruments. ${ }^{8}$ ProTaper NEXT (PTN, Dentsply Maillefer, Ballaigues, Switzerland), the successor of ProTaper Universal (PTU, Dentsply Maillefer) is a full-sequence rotary system. The system consists of 5 shaping instruments with a reduced taper at the tip region $(\mathrm{X} 1: 4 \%, \mathrm{X} 2: 6 \%$, and X3: 7.5\%, X4: $6 \%$, and X5: 6\%) compared to PTU. The instruments are characterized by an offset mass of rotation with various percentages of taper within the full length of the file, which generates a snake-like movement. This motion is claimed to reduce the contact between the file and the dentinal walls, resulting in a reduced screw-in effect and taper lock. Instruments are made of M-Wire, which is believed to increase the flexibility of the instrument and improve cyclic fatigue resistance. ${ }^{9}$

Single-file reciprocating $\mathrm{WO}$ instruments have been shown to be safe when preparing severely curved root canals with results that are comparable with conventional full-sequence rotary instruments. ${ }^{7}$ PTN caused less or similar root canal transportation than traditional instruments used in a continuous rotational motion. ${ }^{10}$ Also, When PTN is compared with WO and PTU, PTN showed better shaping ability, less amount of resin, and better maintenance of apical constriction. ${ }^{11-13}$

The aim of this study was to compare the shaping ability of ProTaper NEXT, WaveOne Primary, and ProTaper Universal instruments in simulated curved canals in resin blocks. The null hypothesis tested was that there is no difference in the shaping ability of the three instruments.

\section{MATERIALS AND METHODS}

\section{Simulated Root Canals}

Forty-eight simulated curved canals were used in this study (Endo Training Block-L, Dentsply Maillefer; taper $=0.02$, apical diameter $=0.15$, length $=16.5 \mathrm{~mm}$, angle and radius of curvature $=60^{\circ}$ and $4.5 \mathrm{~mm}$ measured using the Pruett's technique. ${ }^{14}$ The patency of the canals was confirmed by passing a size $10 \mathrm{~K}$-file just beyond the apex; then, the resin blocks were randomly divided into three groups $(n=16$ canals/group).

\section{Instrumentation}

A new instrument was used for each canal in all groups. Glyde-Prep (Dentsply Maillefer) was used as a lubricant before the utilization of each instrument and distilled water was used for irrigation during preparation using a NaviTip 29 gauge needle (Ultradent Products, South Jordan, UT, USA) inserted $1 \mathrm{~mm}$ short of working length. All canals were instrumented without prior glide path preparation because of the standardized size of resin blocks (taper $=0.02$, apical diameter $=15$ ). Size $10 \mathrm{~K}$-file after each three file strokes to maintain the canal patency.

\section{PTU Group}

ProTaper Universal files were used according to the manufacturer's instructions using a gentle in-and-out motion with an electric and torque-controlled endodontic motor (WaveOne motor, Dentsply Maillefer). Because of the coronal shape of resin blocks, the SX instrument was not used. The instrumentation sequence was $\mathrm{S} 1$ and $\mathrm{S} 2$ at working length (WL) $-1 \mathrm{~mm}$ and F1, F2 at full WL. Once the instrument had negotiated the full WL and rotated freely, it was removed. Each file was used with a brushing motion. Canal patency was checked using a size $10 \mathrm{~K}$-file after each instrument removal. Between each instrument used the canal was irrigated with distilled water.

\section{PTN Group}

All ProTaper NEXT instruments were used with a rotational speed of $300 \mathrm{rpm}$, and the torque was adjusted to $2.0 \mathrm{Ncm}$ using an endodontic motor (WaveOne motor, Dentsply Maillefer). All instruments were used to full working length. The instrumentation sequence was as follows: X1 (size 17, 0.04 taper); X2 (size 25, 0.06 taper); The files were used in a pecking motion (amplitude less than $3 \mathrm{~mm}, 3$ pecks) according to the manufacturer's instructions. The flutes of the instrument were cleaned after 3 in-and-out-movements (pecks). The canal patency was checked using a size $10 \mathrm{~K}$-file after each instrument removal. Between each instrument used the canal was irrigated with distilled water.

\section{WO Group}

The WaveOne Primary file (tip size $=25$, apical taper $=0.08$ ) was used in a reciprocating motion generated by the WaveOne motor (Dentsply Maillefer) in the "WaveOne All" mode. The files were used in a pecking motion (amplitude less than $3 \mathrm{~mm}, 3$ pecks) according to the manufacturer's instructions. The flutes of the instrument were cleaned after every three in-and-out-movements (pecks). The canal patency was checked using a size 10 K-file after every 3 pecks, and the canal was irrigated with distilled water.

All canals were prepared by the same experienced operator. Each instrument was used to prepare a single canal only. 


\section{Image Analysis and Assessment of Canal Preparation}

All canals were injected with black ink (Parker Quink, Parker, France) to obtain a clear preoperative image. The canals were photographed using a digital camera (Sony Alpha DSLR-A100 camera with DSLR-A100 macro lens; Sony, Tokyo, Japan) on a custom fixed stand with constant settings. The canals were rinsed with distilled water before and after instrumentation. The canals were subsequently filled with red ink (Parker Quink) and were photographed again under identical conditions.

The pre- and post-instrumentation images were superimposed into a composite image using a computer software program (Adobe Photoshop Elements 7.0; Adobe Systems, San Jose, CA, USA). A measuring template was superimposed on the composite images. The amount of resin removal as a result of instrumentation was measured using Image J 1.46r software (Wayne Rasband; National Institutes of Health, Bethesda, MD) in a perpendicular manner to the surface of the canal at 22 measuring points (11 on each side of the canal, Fig. 1). The measurement points were arranged in 1-mm steps; points 0 to 3 corresponded to the apical part of the canal, 4 to 7 to the curvature, and points 8 to 10 to the straight coronal part of the canal. A second examiner who was blinded to all experimental groups performed the assessments of the canal shaping images before and after instrumentation. Parameters that were evaluated were total resin removal, centering ability, canal transportation at the apical, curved, and coronal part and preparation time.

\section{Total Resin Removal}

Total resin removal was measured by adding the amount of resin removed from the inner to the amount removed from the outer side of simulated curved canals.

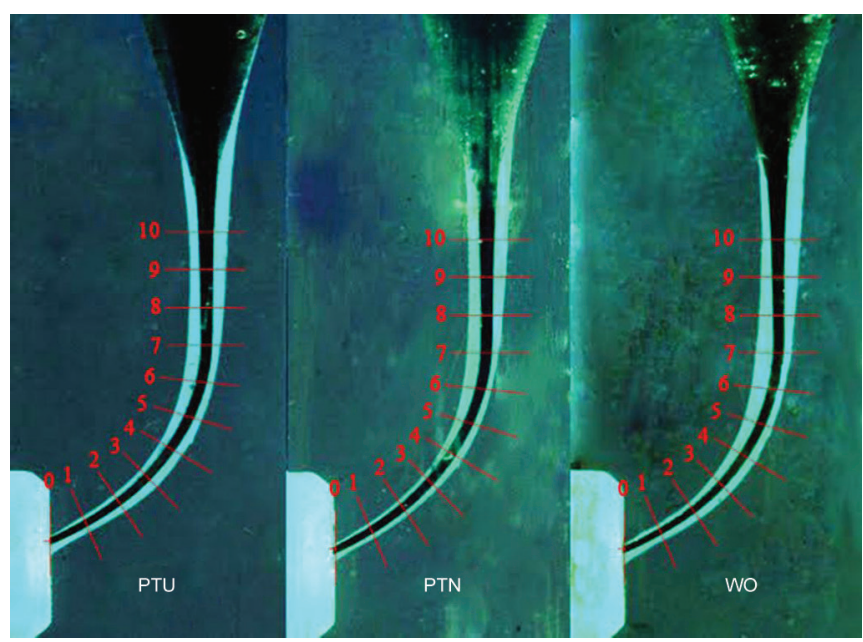

Fig. 1: Superimposed images of canals prepared with ProTaper Universal (PTU), ProTaper NEXT (PTN), and WaveOne Primary (WO)

\section{Centering Ability}

Centering ability assessed for each measuring point by analyzing the amount of resin removed at the inner side versus the outer side using paired t-test $(p<.05)$. Canal preparation with no significant differences between the amounts of resin removed at the inner side compared to the resin amounts removed at the outer side was considered as good centering ability.

Canal transportation at:

- Apical part: Points 0 to 3 were considered for measuring apical transportation by subtracting the amount of resin removed at the inner side from the amount removed at the outer side at each of these four points. A positive value indicated transportation toward the inner side, and a negative value means transportation of the canal toward the outer side.

- Middle part (Curvature): Points 4 to 7 were considered for measuring curvature straightening by subtracting the amount of resin removed at the inner side from the amount removed at the outer side at these points. A positive value indicated curvature straightening.

- Coronal part: Points 8 to 10 were considered for measuring coronal narrowing by subtracting the amount of resin removed at the inner side from the amount removed at the outer side at these points. A positive value indicated main resin removal at the inner side of canal curvature and a negative value indicated removal at the outer side of the orifice.

\section{Preparation Time}

The time for canal preparation, which included total active instrumentation, cleaning of the flutes of the instruments, patency check using a size $10 \mathrm{~K}$-File, and irrigation was recorded.

\section{Instrument Separation and Obvious Shaping Errors}

Two experienced operators examined the prepared resin block under $2 \times$ hand magnifier for any instrument separations or aberration in the shaping of resin blocks.

\section{Statistical Analysis}

After confirming the normality of each set of data using the Kolmogorov-Smirnov and Shapiro-Wilk tests, the data were analyzed using paired t-test, ANOVA and the post hoc Tukey's test. ( $p<0.05$, IBM SPSS Statistics 21; SPSS, Chicago, IL).

\section{RESULTS}

No instrument separated, and no obvious shaping errors were evident following instrumentation of the simulated canals (Fig. 1). 


\section{Total Resin Removal (Table 1)}

Total resin removal was significantly different at points $4,5,6$, and 7 in the curved part of the canals between the three groups and the WO instruments removed the highest amount of resin $(p<0.001)$. The amount of resin removed by PTN was less than the other groups, and this difference was significant at points $2,3,4,5,6,7$ $(p<0.001), 8$, and $10(p<0.01)$ (Graph 1$)$. Total resin removal by WO and PTU was similar at points $0,1,2,3,8,9$, and $10(p>0.05)$.

\section{Centering Ability}

Regarding centering ability PTN had the tendency to remove resin more equally at the inner and outer side of the canal at points $1,2,3$, and $8(p=0.776)$ than the other instruments (WO at point $3(p=0.166)$, and PTU at point 4 ( $p=0.403$ ) only), although the differences were not significant (Graph 2).

Canal transportation at:

- Apical part: PTN created less apical transportation than the other instruments at $0,1,2(p<0.001)$ while PTU and WO were similar at these points ( $p$ values were $0.862,0.497$, and 0.911 , respectively). At point 3 PTN and WO performed similar $(p=0.091)$ but significantly different compared with PTU ( $\mathrm{p}$-values were 0.0001 , and 0.01, respectively, Graph 2).

- Middle part (Curvature): At point 4 PTU transported the canal more than PTN $(p=0.001)$ and WO $(p=0.0001)$. At point 5 PTN and PTU caused similar canal transportation $(p=0.363)$ and WO significantly more transportation than PTN and PTU ( $p$ values were 0.022 , and 0.000 , respectively). At points 6 and 7, there were no significant differences between the three groups ( $p=0.997)$.

- Coronal part: PTN caused less transportation than WO at 8,9 , and 10 and less transportation than PTU at 8 . PTU and WO caused similar transportation at points 8 and 9 ( $p$ values were 0.912 and 0.113 , respectively) but they were different at point $10(p=0.01)$ (Graph 2, $p<0.05$ ).

\section{Preparation Time}

PTU required more time to prepare the canal compared to WO and PTN (Table 2, $p<0.001$ ).

\section{DISCUSSION}

The present study compared the shaping ability of two novel instrumentation techniques; PTN and WO with the well-studied PTU-system in severely curved simulated canals in resin blocks. Although manufacturers recommend a glide path preparation of at least size

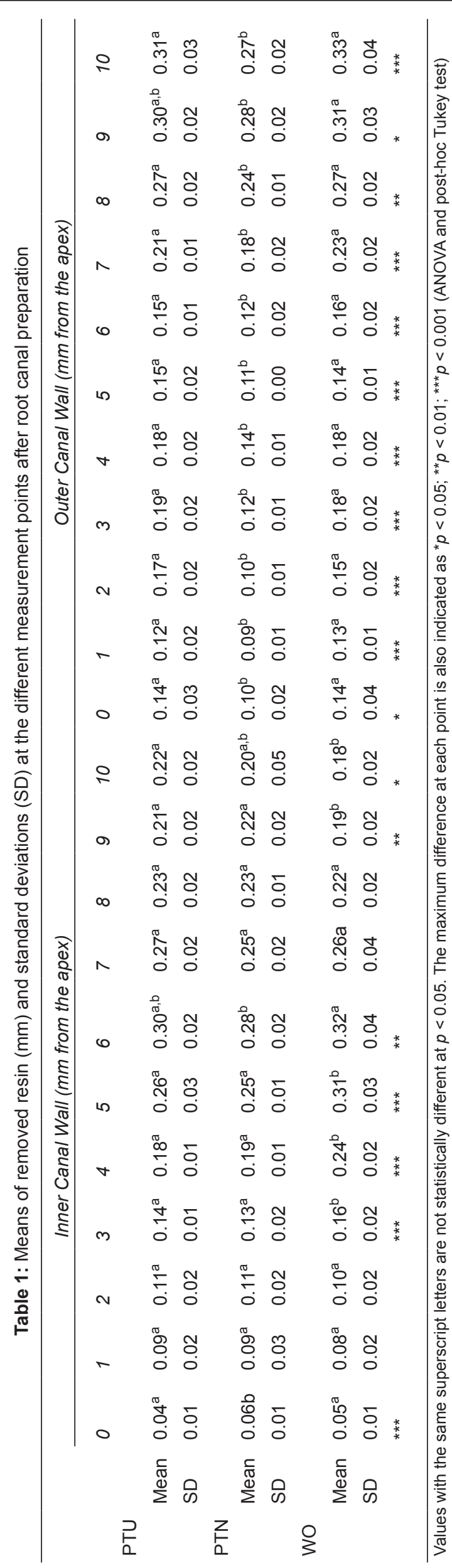




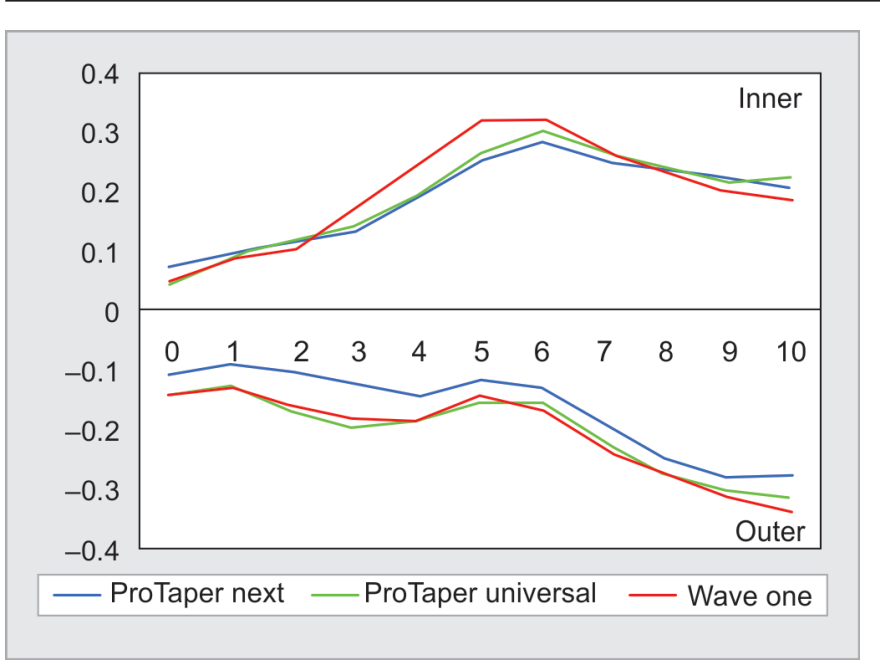

Graph 1: Canal width after preparation with the three instruments at the different measuring points in $\mathrm{mm}$

Table 2: Preparation time of each instrumentation techniques in seconds

\begin{tabular}{ll}
\hline Rotary instruments & Preparation time (Mean \pm SD) \\
\hline ProTaper Universal & $158.3 \mathrm{a} \pm 17.5$ \\
ProTaper Next & $74.3 \mathrm{~b} \pm 9.8$ \\
WaveOne & $75.4 \mathrm{~b} \pm 8.0$
\end{tabular}

Values with the same superscript letters are not statistically different at $p<0.05$.

15 before using these instruments, no prior glide path was created in this study because the diameter of the simulated canals was equal to ISO-size 15 with 0.02 taper. Simulated canals in resin block have been used in numerous studies and their validity as substitutes for extracted human teeth has been verified. ${ }^{15}$ Excellent preand post-instrumentation standardization of simulated canals is one of their main advantages.

The results of the present study showed that all three instruments caused some canal transportation in the apical part, straightening of the curvature, and narrowing of the coronal part of the canal. Filho et al. also showed that both reciprocating and rotating instruments have a tendency to straighten the canal. ${ }^{11}$ In our study, PTN showed the least amount of apical transportation while WO and PTU performed similarly in the apical and coronal parts. Toriano et al. showed less amount of resin removal and better centering ability by PTN when compared with WO. ${ }^{12}$ In the curved part of the canals in our study, WO caused significantly more straightening than PTU and PTN by removing more resin from the inner side of the curvature. Not quite similar, Wu et al. found better shaping ability of PTN at the curved section of simulated canals when compared with PTU and WO. ${ }^{13}$ In the present study, there were no differences between PTU and PTN when shaping the curvature of simulated canals. Therefore, the null hypotheses had to be rejected.

The shaping ability of an instrument is affected by the size, taper, cross-sectional design, metallurgical

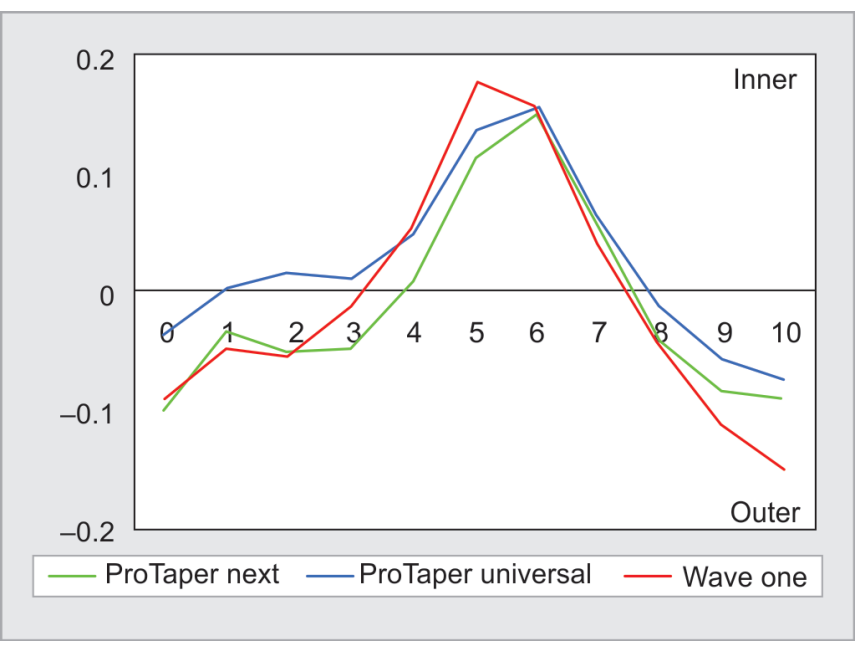

Graph 2: The direction and amount of canal transportation at the different measuring points in $\mathrm{mm}$.

properties, file kinematic, and operator's experience. ${ }^{16-18}$ NiTi endodontic files are mainly made of three types of microstructural phases; austenite that is the strong and hard phase of NiTi wires, martensite which is the flexible phase and R-phase. The microstructures of PTU are mainly austenite ${ }^{19}$ while the major microstructural phase of WO and PTN is martensite. ${ }^{20}$ Since both PTN and WO are made of the same alloy (M-wire) it is reasonable to assume that the differences in their shaping ability were probably due to differences in taper, cross-sectional design, and their working motion.

In the present study, the apical preparation size was standardized to size 25 in all groups. However, the instruments used had different tapers along their length. The PTU S1 and S2 instruments have a progressive taper while F1 and F2 have regressive tapers. ${ }^{21}$ The taper of WO along the first $3 \mathrm{~mm}$ from the tip is 0.08 , which regresses along the working part to a taper of 0.055 . The PTN X1 and $\mathrm{X} 2$ instruments have a progressive taper at the tip region and middle part of the instrument that decreases towards the shaft. ${ }^{22}$ The fact that WO and the last PTU used show a taper of 0.08 at their tip region might have contributed to similar shaping effects of these instruments in the apical part of the canal. The less tapered PTN files performed significantly better in the apical part and this finding is consistent with the results of other studies. ${ }^{23,24}$ Another explanation for the improved shaping ability of PTN in the apical part of the curved canals may be the unique off-centered rectangular cross-section of the instruments that gives the file a snake-like motion. ${ }^{25}$

In the present study, no significant differences between single-file reciprocating WaveOne Primary instruments and PTU regarding their overall shaping ability were obtained, which is consistent with previous studies. ${ }^{7,18,26}$ However, in the curved part of the canal (at the level of point 5), the use of WO resulted in more straightening than with the other instruments. 
This finding corroborates the results of a previous investigation. ${ }^{26}$

No instrument fractured during the present study. Preparation time depends on various factors such as a number of instruments used, operator's experience, and experimental set-up. ${ }^{27}$ In the present study, the preparation time included active instrumentation, changing of instruments, cleaning the flutes, patency checking with size 10 stainless steel K-Files, and irrigation. There were no significant differences regarding preparation time between PTN and WO, but PTU required more time to prepare the simulated root canals. This difference was due to the fact that four ProTaper Universal instruments were required for complete shaping the canals. Considering the differences between resin blocks and natural tooth structure, ${ }^{28}$ similar results have been reported when natural teeth were prepared with PTN (72.5 seconds). ${ }^{29}$ In this study, all instruments were safe to use and preserved the original canal shape well. In the apical part of the canals, PTN obtained the best results with regard to canal transportation.

The limitation to the present study is using resin block and its differences with natural teeth. Dentin is harder than the resin of simulated canals, and the type of debris forming during instrumentation is different. Consequently, instrumentation of natural teeth might not be similar to resin blocks. In addition, natural teeth usually present more complex anatomy than a single patent canal in resin block. ${ }^{27,30}$ In clinical scenarios clinicians would be dealing with root canals system which is not as simple as a single canal presented in resin blocks. ${ }^{31}$

\section{CONCLUSION}

Under the condition of the study, all instruments were safe to use and preserved the original canal shape well. In the apical part of the canals, PTN obtained the best results with regard to canal transportation.

\section{CLINICAL SIGNIFICANCE}

All of the rotary instruments were safe in preparing severely curved canals, and PTN showed better preparation of apical part of the canal.

\section{REFERENCES}

1. Schilder H. Cleaning and shaping the root canal. Dent Clin North Am. 1974 Apr;18:269-296.

2. Sanfelice CM, da Costa FB, Reis Só MV, et al. Effects of Four Instruments on Coronal Pre-enlargement by Using Cone Beam Computed Tomography. J Endod. 2010 May;36: 858-861.

3. Schäfer E, Florek H. Efficiency of rotary nickel-titanium K3 instruments compared with stainless steel hand K-Flexofile.
Part 1. Shaping ability in simulated curved canals. Int Endod J. 2003 Mar;36:199-207.

4. Baugh D, Wallace J. The role of apical instrumentation in root canal treatment: a review of the literature. J Endod. 2005 May;31:333-340.

5. Peters OA. Current challenges and concepts in the preparation of root canal systems: a review. J Endod. 2004 Aug;30: 559-567.

6. Yared G. Canal preparation using only one Ni-Ti rotary instrument: preliminary observations. Int Endod J. 2008 Apr;41:339-344.

7. Bürklein S, Hinschitza K, Dammaschke T, et al. Shaping ability and cleaning effectiveness of two single-file systems in severely curved root canals of extracted teeth: Reciproc and WaveOne versus Mtwo and ProTaper. Int Endod J. 2012 May;45:449-461.

8. Varela-Patino P, Ibanez-Parraga A, Rivas-Mundina B, et al. Alternating versus continuous rotation: a comparative study of the effect on instrument life. J Endod. 2010 Jan;36:157-159.

9. Pereira ES, Viana AC, Buono VT, et al. Behavior of nickeltitanium instruments manufactured with different thermal treatments. J Endod. 2015 Jan;41:67-71.

10. Bürklein S, Mathey D, Schäfer E. Shaping ability of ProTaper NEXT and BT-RaCe nickel-titanium instruments in severely curved root canals. Int Endod J. 2015 Aug;48:774-781.

11. Maia Filho EM, Dos Reis Santos RM, Lima DM, et al. Shaping Ability of ProTaper Next, WaveOne, and Reciproc in Simulated Root Canals. J Contemp Dent Pract. 2016 Nov;17(11):902906.

12. Troiano G, Dioguardi M, Cocco A, et al. Centering ability of ProTaper Next and WaveOne Classic in J-Shape simulated root canals. Sci World J. 2016;2016.

13. Wu H, Peng C, Bai Y, et al. Shaping ability of ProTaper Universal, WaveOne and ProTaper Next in simulated L-shaped and S-shaped root canals. BMC Oral health. 2015 Dec;15(1):27.

14. Pruett JP, Clement DJ Carnes DL, Jr. Cyclic fatigue testing of nickel-titanium endodontic instruments. J Endod. 1997 Feb;23:77-85.

15. Lim KC, Webber J. The validity of simulated root canals for the investigation of the prepared root canal shape. Int Endod J. 1985 Oct; $18: 240-246$.

16. Peters OA, Schönenberger K, Laib A. Effects of four Ni-Ti preparation techniques on root canal geometry assessed by micro computed tomography. Int Endod J. 2001 Apr;34:221-30.

17. Peters OA, Paque F. Root canal preparation of maxillary molars with the self-adjusting file: a micro-computed tomography study. J Endod. 2011 Jan;37:53-57.

18. Zhao D, Shen Y, Peng B, et al. Root canal preparation of mandibular molars with 3 nickel-titanium rotary instruments: a micro-computed tomographic study. J Endod. 2014 Nov;40:1860-1864.

19. Shen Y, Zhou HM, Zheng YF, et al. Current challenges and concepts of the thermomechanical treatment of nickeltitanium instruments. J Endod. 2013 Feb;39:163-172.

20. Pereira ES, Gomes RO, Leroy AM, et al. Mechanical behavior of M-Wire and conventional NiTi wire used to manufacture rotary endodontic instruments. Dent Mater. 2013 Dec;29:e318e324.

21. Schäfer E, Vlassis M. Comparative investigation of two rotary nickel-titanium instruments: ProTaper versus RaCe. Part 2. Cleaning effectiveness and shaping ability in severely curved root canals of extracted teeth. Int Endod J. 2004 Apr;37:239-248. 
22. Ha JH, Cheung GS, Versluis A, et al. 'Screw-in' tendency of rotary nickel-titanium files due to design geometry. Int Endod J. 2015 Jul;48:666-672.

23. Bürklein S, Benten S, Schäfer E. Shaping ability of different single-file systems in severely curved root canals of extracted teeth. Int Endod J. 2013 Jul;46:590-597.

24. Saber SE, Nagy MM, Schäfer E. Comparative evaluation of the shaping ability of WaveOne, Reciproc and OneShape single-file systems in severely curved root canals of extracted teeth. Int Endod J. 2015 Jan;48:109-114.

25. Elnaghy AM. Cyclic fatigue resistance of ProTaper Next nickeltitanium rotary files. Int Endod J. 2014 Nov;47:1034-1039.

26. Wu H, Peng C, Bai Y, et al. Shaping ability of ProTaper Universal, WaveOne and ProTaper Next in simulated L-shaped and S-shaped root canals. BMC Oral Health. 2015 Mar; 15:27.
27. Hülsmann M, Peters OA, Dummer PMH. Mechanical preparation of root canals: shaping goals, techniques and means. Endod Topics. 2005 Aug;10:30-76.

28. Khalilak Z, Fallahdoost A, Dadresanfar B, et al. Comparison of extracted teeth and simulated resin blocks on apical canal transportation. Iran Endod J. 2008 Fall;3: 109-112.

29. Saber SE, Nagy MM, Schäfer E. Comparative evaluation of the shaping ability of ProTaper Next, iRaCe and Hyflex CM rotary NiTi files in severely curved root canals. Int Endod J. 2015 Feb;48:131-136.

30. Lim KC, Webber J. The validity of simulated root canals for the investigation of the prepared root canal shape. Int Endod J. 1985;18(4):240-246.

31. Carrotte P. Endodontics: Part 4 Morphology of the root canal system. Br Dent J. 2004;197(7):379-383. 